\title{
The new CCD Zenith Tube
}

\author{
C. Ron, V. Štefka and J. Vondrák \\ Astronomical Institute of the Academy of Sciences of the Czech Republic, \\ Boční II, 14131 Prague, Czech Republic \\ e-mail: ron@ig.cas.cz, stefka@ig.cas.cz, vondrak@ig.cas.cz
}

\begin{abstract}
The reconstruction of the Photographic Zenith Tube (PZT) at Ondřejov has been finished recently. The main improvement of the instrument consists in the replacement of the photographic plate with the CCD chip, and a completely new electronic control system. In addition to the astrometric use of the observations we intend to derive the variations of the local vertical and compare them with gravimetric observations of the nearby station Pecný.
\end{abstract}

Keywords. astrometry, telescopes

\section{Introduction}

In 2004, after more than 30 years of the permanent observations of PZT at Ondřejov Observatory we were confronted with the question either to close the observations and dismount the instrument or to attempt to raise money for a radical reconstruction. The project was financially supported by the Academy of Sciences of the Czech Republic.

\section{The original PZT}

The Photographic Zenith Tube (PZT) manufactured by Carl Zeiss, Jena in 1969 was installed at the Ondřejov Observatory in 1972. The permanent observations started in 1973 and interrupted at the end of 2005. The instrument, described in detail by Weber (1977), has an objective $250 \mathrm{~mm}$ in diameter and $3780 \mathrm{~mm}$ in focal length. The photographic plate was placed in a carriage which followed the star during the exposure. The synchronization with UTC was done by a crystal-controlled phonic motor. The controlling quartz clock was synchronized with the time signal OMA50 till 1993, and with DCF77 afterwards. During the whole period of 33 years 306 stars of 4.6-11.0 mag were observed. Several readjustments of the working catalogue were done by Weberová \& Weber (1976), Vondrák (1980), Ron \& Vondrák (1985), and finally Ron \& Vondrák (2003). Due to precession, stars are leaving the visual field of the instrument and less than 200 stars from the catalogue were observable in 2005 . The photographic plates $(40 \times 40 \mathrm{~mm})$ were measured at the measuring machine ASCORECORD and the reduction of the observation after Vondrák (1978) was used. The average rms of about $7 \mu \mathrm{m}$ was reached in the last few years.

\section{The new CCD Zenith Tube}

The reconstruction started in 2006 and was finished in July 2007. The principle of the PZT has not been changed. The photographic plate was replaced by the CCD chip, Kodak KAF 6303 , with the size $20 \times 30 \mathrm{~mm}$ and $2048 \times 3072$ pixels. The CCD chip is smaller than the original photographic plate so the visual field is narrower by about $3^{\prime}$ in declination. The mechanics of the instrument has been simplified substantially using the stepper motor to move the carriage with the chip. The exposure time is optional 

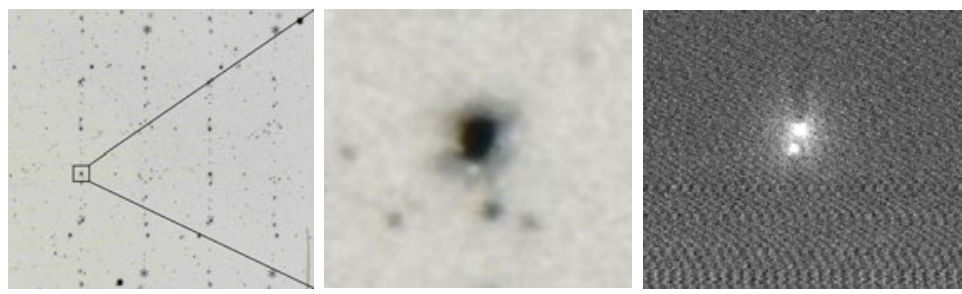

Figure 1. The binary HIP 106038 at the photographic plate (2 figures on the left) and at the CCD (on the right). The distance of the components is $9^{\prime \prime}$ ( $1^{\prime \prime}$ corresponds to $18 \mu \mathrm{m}$ or 2 pixels on the chip). The components (9.5 and $10.6 \mathrm{mag}$ ) were not separable on photographic plates.

from $2 \mathrm{~s}$ for the bright stars (4-5mag) to $16 \mathrm{~s}$ for the faintest stars. To speed up the readout time of a chip, only a half of image with the observed star is saved after each exposure. This enables to simplify requirements for the cooling of the chip. The cooling is done by two connected Peltier coolers located outside the instrument. The time is synchronized with GPG24A, the precise time and frequency generator synchronized with the UTC time scale via GPS satellite system. The device generates second time marks with the accuracy better than $0.1 \mu \mathrm{s}$, which is used to start the exposures directly. The working catalogue Ron \& Vondrák (2003) has been supplied with new stars taken from the catalogue ARIHIP (Wielen et al. 2001) and comprises now 325 stars up to 12 mag. The observations started in August 2007 and 15 observing nights have been performed till October 2007. The coordinates of the optical center of the star image are determined using program SExtractor (Bertin 2007). The reductions of observations after Vondrák (1978) is used again with a few modifications and the average rms reaching $3-4 \mu \mathrm{m}$.

The CCD Zenith Tube in Ondřejov will be used for astrometry and to determine the variation of the local vertical, both in automatic operational mode. The variations of the vertical will be compared with gravimetric observations at the nearby station Pecný equipped with the absolute and superconducting gravimeters. The substantial improvement of the resolution and sensitivity (up to $15 \mathrm{mag}$ ) is achieved, see Fig. 1 and the accuracy is better about $2-3$ times.

\section{Acknowledgements}

The contribution of M. Wudia ( $†$ in July, 2007) to the successful reconstruction of PZT is indubitable. This study was supported through the Research plan AV0Z10030501 of the Academy of Sciences of the Czech Republic and through the grant LC506 of the Ministry of Education, Youth and Sports of the Czech Republic. The catalogue update done by M. Jovanović and I. Milić from the University of Belgrade during their stay at Ondřejov observatory is appreciated.

\section{References}

Bertin, E. 2007, http://terrapix.iap.fr/soft.sextractor

Ron, C., \& Vondrák, J. 1985, Bull. Astron. Inst. Czechosl., 36, 289

Ron, C., \& Vondrák, J. 2003, in Proc. Journées 2002 SRST, Bucharest, 191

Vondrák, J. 1978, Bull. Astron. Inst. Czechosl., 29, 97

Vondrák, J. 1980, Bull. Astron. Inst. Czechosl., 31, 89

Weber, R. 1977, Jenaer Rundschau, 22, 92

Weberová, L. \& Weber, R. 1976, Wiss. Z. Tech. Univers. Dresden, 25, 919.

Wielen, R., Schwan, H., Dettbarn, C., Lenhardt, H., Jahreiß, H., Jährling, R., \& Khalisi, E. 2001, Veröff. Astron. Rechen-Inst. Heidelberg, 40, Kommissions-Verlag G. Braun, Karlsruhe. 